\title{
Economic Analysis of Robots Employment in Building
}

\author{
Abraham Warszawski and Yehiel Rosenfeld \\ Faculty of Civil Engineering and National Building Research Institute \\ Technion - Israel Institute of Technology \\ Haifa 32000, ISRAEL \\ Tel/fax. 972-48293025, or 972-4-8292363 \\ E-mail: cvrabwa@tx.technion.ac.il
}

\begin{abstract}
The paper presents a complete and a simplified model for the economic analysis of robots employment on building sites. Four generic types of building robots are analyzed with the aid of the model and of the available productivity data, which have been published to-date by developers and users of building robots. General conclusions are presented with respect to the feasibility of employment of these four types of robots on building sites: (1) exterior finishing robots, (2) horizontal finishing robots, (3) interior finishing robots, and (4) assembling-handling robots.
\end{abstract}

\section{1: Introduction}

The objective of the paper is to present a model for a methodological analysis of the feasibility of rabots employment in building, and to draw, with the aid of the model, some general conclusions with respect to the major robot types, which have been developed and employed to date in building construction.

The paper starts with the presentation of the model in its general form, that takes into account almost all cost and benefit components when compared with conventional construction. The parameters of the model - dependent on the nature of the robot, on the nature of its task, on the mode of its employment and on the nature of the building project - are examined. The robot parameters include the cost of investment, the operating expenses, the maintenance expenses, the costs of robot transfers between building sites, between locations on site, and between work stations. The project parameters include the quantity of work on an average site, on a floor level and at a work station. The task parameters include the productivity of the robot and of human operators for the particular task. The general parameters involve the cost of labor - skilled and non-skilled - and the annual extent of the total hours of robot employment.

Subsequently, the model is simplified by introducing some assumptions with respect to the nature of the building projects in which the robot is employed. Then, it is applied with respect to four major robot types: exterior wall finishers, horizontal slab finishers, building interior finishers, and material handling robots. The analysis is based on data obtained from actual development and application cases.

Conclusions are drawn with respect to each type of the robots, in order to indicate the feasibility range of their application.

\section{2: Cost of robotized work}

The economic feasibility of robotizing construction work, depends on the associated costs and benefits, when compared with conventional construction methods [21]. It can be examined at different levels - macro and micro - from various perspectives, e.g. that of the national economy, the construction industry, the contractor, the owner and the end-user of the facility. The focus of this paper is mainly on the direct costs and benefits to the constructor, who has to make the decision whether to invest in a specific robotic system.

The total cost (for the constructor) of robotizing a specific task, is composed of the direct cost of the robotized work and the indirect costs: the capital cost of the robotized system, the cost of maintenance of the robot, and the cost of the robot's setup and transfers. If a robot is employed for different works on site, then the indirect cost is allocated accordingly to each work. The total cost, $c_{r}$, of robotized work per unit can be calculated from:

(1) $c_{r}=C_{r s} /\left(H^{*} Q_{h}\right)+C_{d} / Q_{h}+c_{t}+C_{M} /\left(H^{*} Q_{h}\right)$

with: 
$\mathrm{C}_{\mathrm{rs}}$ - capital cost of the robotized system, per year, as calculated with eq. (2).

$Q_{h}$ - output of the robotized system, per hour.

$\mathrm{H}$ - number of hours the robot is employed per year.

$\mathrm{C}_{d}$ - direct cost of the robot per hour - as calculated with eq. (3).

$c_{t}$ - cost of transfers per unit - as calculated with eq. (4).

$C_{M}$ - annual maintenance cost, which is often calculated as a percentage of the initial investment. It is composed of both routine - daily, weekly, etc. - maintenance of the robot, as well as the cost of its malfunction and repairs. The latter also includes indirect losses of income during these periods.

\section{1: Capital cost}

The annual capital cost, $\mathrm{C}_{\mathrm{rs}}$, of the robotic system includes the depreciation of the robot and the interest on the investment in its purchase and/or development. The first component of eq. (2) distributes the net investment in the robotic system (purchase and development minus its terminal value) over $\mathbf{n}$ years of its economic life. The second component of eq. (2) reflects the annual loss of interest on $\mathbf{L}$.

$$
C_{r s}=(P-L) * p r(i, n)+L * i
$$

with:

$P$ - investment in the robotized system (the robot and its peripheral devices).

$\mathrm{L}$ - terminal value of the system at the end of its economic life.

$\mathrm{n}$ - the economic life span of the robot (in years).

$\operatorname{pr}(\mathrm{i}, \mathrm{n})=(1+\mathrm{i})^{\mathrm{n}} /\left[(1+\mathrm{i})^{\mathrm{n}}-1\right]$ - capital recovery factor over a period of $n$ years with annual interest rate $i$.

\section{2: Direct cost}

The direct cost, $C_{d}$, varying directly with the number of work hours, includes the cost of the robot's operator, the expenses of the operation of the robot, the cost of materials, and the cost of auxiliary labor necessary to assist the robotized work. The auxiliary labor may be needed for materials handling, or for complementing of the robotic work in places that are unaccessible to the robot, or in partial tasks that are illstructured for robotic work.

The direct cost of robotized work per hour, $C_{d}$, can be calculated from:

$$
\text { (3) } \mathrm{C}_{\mathrm{d}}=\mathrm{C}_{\mathrm{o}}+\mathrm{C}_{\mathrm{e}}+\mathrm{c}_{\mathrm{mt}} * \mathrm{Q}_{\mathrm{h}}+\mathrm{c}_{\mathrm{x}}^{*} \mathrm{Q}_{\mathrm{h}}
$$

with:

$C_{0}$ - the cost of an operator (or a skilled worker) per hour. It depends on the mode of control of the robot: whether an operator is needed continuously for each robot, or whether the operator can perform simulataneously additional tasks, such as auxiliary work, or overseeing the work of other robots. In the latter case this cost component should be reduced accordingly.

$\mathrm{C}_{\mathrm{e}}$ - the cost of electricity, fuel, or other resources, needed for the operation of the robot, per hour.

$c_{\mathrm{mt}}$ - the cost of of materials, per work unit.

$\mathrm{C}_{\mathrm{x}}$ - the cost of auxiliary labor per work unit. The auxiliary labor may be needed to handle materials, or complement the robot's work.

\section{3: Transfer cost}

The cost of setup and transfers includes the setup on site, the transfer of the robot between different locations (floors, buildings) and - in the case of a robot employed from temporary workstations - the traveling of the robot between the stations at each location. The setup cost of a robot on site includes the transportation of the robot to and from the site, its installation on site, and the cost of all organizational adaptations that are needed to enable robotized work on site.

The setup and transfer cost of the robot per work unit, $c_{t}$, can be calculated from these components as follows:

(4) $c_{t}=C_{s} / Q_{s}+C_{1} / Q_{1}+C_{w} / Q_{w}$

$\mathrm{C}_{\mathrm{s}}$ - the average setup cost of the robot on site (allocated to the particular work).

$Q_{s}$ - the number of work units of the robot on an average site.

$\mathrm{C}_{1}$ - the average transfer cost of the robot between locations (floors or buildings) on site.

$Q_{1}$ - the average number of work units for the robot per location. 
$\mathrm{C}_{\mathrm{w}}$ - the average traveling cost of the robot between workstations. This cost component applies only to robots that operate from temporary workstations.

$Q_{w}$ - the average number of work units per workstation.

\section{4: Summary of the cost components}

It may be seen that the cost of robotized construction depends on four types of parameters:

a. Parameters dependent on the nature of work to be done: the robot's productivity (in terms of the number of work units produced per hour), the technological adaptations necessary for robotized performance of the task, and the auxiliary work needed. The more "robot friendly" is the task, the higher will be its productivity (output per hour) in the performance of the task, and the lower will be the cost of adaptation and auxiliary labor.

b. Parameters dependent on the nature of the robotized system: the investment, the operation and the maintenance costs of the robot, and its setup and transfer costs on site. A "user friendly" robotized system is inexpensive to operate, easy to maintain, and - most important - can, due to its versatiliy, be employed for many hours per year. High versatility, means adaptibility of the robot to different works and to different configurations of buildings.

c. Parameters dependent on the nature of the construction projects: the amount of work on site that is suitable to robotized construction, and the dispersion of work among defferent locations and work stations. The dispersion of work may largely depend on the accessibility of spaces within the building to the robot. A "robot friendly" project is characterized by large amount of work suitable for the robot, few and easy transfers and minimal adaptation cost on site.

d. The number of employment hours of the robot per year. This last parameter is very important, considering the high fixed cost of the robot, which has to be distributed over a given number of its work hours, and thence - of its work units.

The cost of robotized construction, calculated in this manner, has to be evaluated in light of the benefits of robotized construction.

The benefits include "tangible" benefits and "intangible" benefits. The tangible benefits are primarily the cost of labor saved due to the robot's employment and can be readily evaluated in direct money terms. The "intangible" benefits are more difficult to measure objectively in money terms

\section{3: A general model of economic feasibility}

\section{1: Breakeven calculations with simplified assumptions}

In order to draw some general conclusions, and make the analysis applicable to different types of robots and different types of building sites, some simplifications can be introduced. It was found that in most cases the highest transfer cost component (see eq. 4) is the transfer cost between sites, while the costs of transfer between locations on site and between workstations are less significant, and can be included in the calculations of the robot's output per hour. The transfer cost was therefore assumed here, for simplicity, as directly proportional to the number of transfers between sites. Also for simplicity (without changing significantly the results of the calculations) the salvage value of the robot, $\mathrm{L}$, was assumed to be zero, and an average labor wage rate for all types of warkers was assumed.

These assumptions enable to calculate, fairly conveniently, the approximate maximum feasible investment in a robot under different circumstances pertainning to: average labor wages, the number of the robot's work hours per year, the size of an average project and the cost per transfer of the robot. The maximum feasible investment is calculated by eq. (5), as a breakeven value, $\mathrm{V}$, of the investment for which the benefits, $B$, from the use of the robot cover its cost, C:

$$
\text { (5) } \begin{aligned}
\mathrm{C} & =\mathrm{V}^{*} \operatorname{pr}(\mathrm{i}, \mathrm{n})+\mathrm{C}_{\mathrm{M}}+(\mathrm{H} / \mathrm{h}) * \mathrm{C}_{\mathrm{t}}+\mathrm{H}^{*} \mathrm{C}_{\mathrm{e}}= \\
=\mathrm{B} & =\mathrm{H}^{*} \mathrm{k}^{*} \mathrm{C}_{1}+\mathrm{I}
\end{aligned}
$$

with :

$\mathrm{V}$ - the breakeven value of the robot, i.e. the maximum economically feasible investment in the robot.

$\operatorname{pr}(\mathrm{i}, \mathrm{n})$ - capital recovery factor of the investment over a period of $\mathbf{n}$ years with interest rate $i$.

$C_{M}-$ cost of maintenance per year.

$\mathrm{H}$ - total number of working hours of the robot per year.

h - average number of the robot's working hours per site.

$C_{\mathrm{q}}$ - average setup and transfer cost per site (all types of transfers). 
$\mathrm{C}_{\mathrm{e}}$ - operating cost of the robot per hour.

k - number of labor hours saved per each hour of robotized work.

$C_{l}$ - average labor cost per hour.

I - intangible gains of robotization per year.

The feasibility of investment in robotized systems, will be determined in the next section, considering (initially) only the tangible benefits of labor savings.

The major variables that determine the economic feasibility of the employment of a given robot can be seen from eq. (5). They are: savings in labor cost due to the robot's work (the number of manual work hours saved per robot's hour multiplied by the workers' average wage per hour), the number of robot's employment hours per year, and the transfer cost of the robot (number of sites per year multiplied by the average transfer cost per site).

The maximum feasible investment, $\mathrm{V}$ (the breakeven value of the robot), calculated with eq. (5) for different values of these variables, are shown in Table 1, assuming the following parameter values:

$\mathrm{C}_{\mathrm{t}}=\$ 500$ per site (assuming that the transfer costs on site are small).

$C_{e}=\$ 2$ (for energy) per hour

$C_{M}=0.1 \mathrm{~V}+0.06 \mathrm{H}^{*} \mathrm{C}_{\mathrm{l}}$ (i.e. the annual expenses for labor, parts and downtime during repairs are estimated at $10 \%$ of the initial investment, while the routine maintenance is assumed to be equivalent to the cost of $6 \%$ of the working hours of the robot per year.

$$
\begin{aligned}
& \mathrm{i}=7 \% \text { per year } \\
& \mathrm{n}=5 \text { years } \\
& \mathrm{C}_{1}=\$ 25 \text { per hour. }
\end{aligned}
$$

The values in Table 1 are conservative; they do not take into account the intangible benefits of robotization.

Table 1 - Tangible value of the robot to the user for different labor savings and labor costs.

\begin{tabular}{|r|rrr|rrr|rrr|rrr|}
\hline $\begin{array}{c}H \\
\text { (hrs } / y r)\end{array}$ & $k$ & $H / h$ & $V(\$)$ & $k$ & $H / h$ & $V(\$)$ & $k$ & $H / h$ & $V(\$)$ & $k$ & $H / h$ & $V(\$)$ \\
\hline 500 & 1 & 5 & 24,000 & 1.5 & 5 & 42,181 & 2 & 5 & 60,362 & 3 & 5 & 96,724 \\
500 & 1 & 10 & 16,727 & 1.5 & 10 & 34,908 & 2 & 10 & 53,089 & 3 & 10 & 89,452 \\
500 & 1 & 20 & 2182 & 1.5 & 20 & 20,363 & 2 & 20 & 38,544 & 3 & 20 & 74,907 \\
500 & 1 & 40 & $-26,908$ & 1.5 & 40 & $-8,727$ & 2 & 40 & 9,454 & 3 & 40 & 45,817 \\
& & & & & & & & & & & & \\
1000 & 1 & 5 & 55,271 & 1.5 & 5 & 91,634 & 2 & 5 & 127,996 & 3 & 5 & 200,721 \\
1000 & 1 & 10 & 47,998 & 1.5 & 10 & 84,361 & 2 & 10 & 120,724 & 3 & 10 & 193,449 \\
1000 & 1 & 20 & 33,454 & 1.5 & 20 & 69,816 & 2 & 20 & 106,179 & 3 & 20 & 178,904 \\
1000 & 1 & 40 & 4,364 & 1.5 & 40 & 40,726 & 2 & 40 & 77,089 & 3 & 40 & 149,814 \\
& & & & & & & & & & & & \\
1500 & 1 & 5 & 86,543 & 1.5 & 5 & 141,087 & 2 & 5 & 195,630 & 3 & 5 & 304,718 \\
1500 & 1 & 10 & 79,270 & 1.5 & 10 & 133,614 & 2 & 10 & 188,358 & 3 & 10 & 297,445 \\
1500 & 1 & 20 & 64,725 & 1.5 & 20 & 119,269 & 2 & 20 & 173,813 & 3 & 20 & 282,900 \\
1500 & 1 & 40 & 35,635 & 1.5 & 40 & 90,179 & 2 & 40 & 144,723 & 3 & 40 & 253,810 \\
\hline
\end{tabular}

The analysis can be conveniently applied to all types of robots. It will now be applied to examine the feasibility of the vertical (exterior wall painting), horizontal (floor levelling) and interior finishing (multipurpose) robots. The case of an asembling handling robot will also be examined.

The productivity data for the first two types of robots was taken from information supplied by their developers. The information for productivity and cost of the interior finishing robot and the assembling - handling robot was primarily collected during their development by the authors, and suppelmented by other related sources.

\section{2: Exterior finishing robot}

The reported average output of a vertical finisher is c. $45-50 \mathrm{~m}^{2}$ per hour $\left(70-150 \mathrm{~m}^{2}\right.$ per hour per coat) and it saves 2-3 workers $[4,20]$. Let us assume that an average building in which it will be employed is 8 
stories high, has a floor area of $1,000 \mathrm{~m}^{2}$ per story, and its gross facade area is c. $3,200 \mathrm{~m}^{2}$ ( $40 \%$ of the floor area). Let us further assume that such a building requires 3 coats of paint at an average rate of 130-150 $\mathrm{m}^{2}$ per hour per coat, that will add-up to 6474 robot hours per building. To be employed 1,500 work hours per year, the robot must paint each year about 20-24 buildings of this size. If such magnitude of work can be assured to the robot over its life-cycle, its worth to the user (see Table 1), at labor cost of $\$ 25$ per hour, is about $\$ 174,000$ (for saving 2 workers).

Assuming only one third of this utilization - i.e. 500 hours per year on 6-10 buildings - it still worth $\$ 55,000$ - $\$ 60,000$ to the user. One must, however, take into account that a supply of 10 buildings of this size per year - suitable for robot employment - may not be easy, unless appropriate building methods, that will make them "robot friendly", are adopted.

We will now proceed to examine the sensitivity of the robot's value to changes in the transfer cost and the labor rate: Should the transfer cost amount to $\$ 1,000$ per transfer (instead of $\$ 500$ as assumed), the value of the robot for 1,500 hours of work per year (and 20-25 transfers) will drop to $\$ 145,000$, and in the case of 500 hours (and 5-10 transfers) - to $\$ 45,000$ - $\$ 50,000$. This is still within the economic feasibility range

The feasible investment is even more sensitive to the cost of labor: For average labor rate of $\$ 12.5$ per hour (instead of $\$ 25$ ) the value of the robot at 1,500 hours of utilization and 20-25 transfers will be $\$ 68,000$, and at 500 hours and 5-10 transfers - only $\$ 20,000$. If the robot can be improved to replace more workers, as envisioned $[4,7,9,19]$, then its economic feasibility will substantially improve, even with low labor rates. According to one detailed report [17] one robot plus 3 workers should be able to perform equally to a team of 8 men.

\section{3: Horizontal finishing robot}

The output of advanced models of horizontal finishers is c. $500 \mathrm{~m}^{2}$ per hour, and one robot can save the labor of 3 workers [e.g. 8, 11]. Let us assume again that an average building in which it will be employed is, as in the former case, $\mathbf{8}$ stories high with a gross area of $8,000 \mathrm{~m}^{2}$. Such a building can utilize only 16 robot hours. In order to accumulate 1,500 working hours, the robot will have to complete 90 such buildings per year, which will probably be too much, considering the transfer and setup time needed (the robot will have to be brought to the site for each floor separately). It is, perhaps, more conceivable that the robot will be employed 500 hours and complete $20-40$ buildings per year (which will still require 150-300 trnasfers). In such case it will worth to the user - assuming at least $\$ 1,000$ per site for 8 transfers - merely $\$ 10,000$ to $\$ 30,000$, which will make it certainly infeasible.
The situation will improve if the robot is employed in very large buildings with daily casts of large floor segments, or where the pace of progress of floor casting is one per 1-2 working days. In such cases the robot can be left on site between castings, and assuming then an average transfer cost per site of $\$ 500$, its value will increase to $\$ 50,000-\$ 60,000$, which is within the feasibility range. However, a stable supply of 250,000 $\mathrm{m}^{2}$ of such buildings per year will still require prodigous marketing and logistic efforts. It results that the employment of this robot type will be feasible in buildings (or other concrete structures) with very large floor areas - in the range of $5,000-10,000 \mathrm{~m}^{2}$.

The employment of the robot will certainly be infeasible if the cost of labor is $\$ 12.5$ per hour.

\section{4: Interior Finishing Robot}

The development of TAMIR - Technion Autonomous Multipurpose Interior Robot [15, 23, 24] demonstrated that a variety of interior finishing tasks, such as building of walls, setting tiles, painting and plastering can be performed by the same robot, by changing its end-effectors and peripheral systems. The firsthand experience of the authors with this development from concept to a full-size prototype, and the intensive technological, organizational and economic research that accompanied it, led them to the conclusion that it will be more advantageous under the prevailing conditions to havee the robot act under close human supervision, with fairly frequent interventions for assissting the robot in transfers, calibrations, materials supply etc.. Nevertheless, despite the constant presence of an operator, the robot can still save the wages of 2 - 4 additional workers. Moreover, it will have sufficient work to do for more than an entire year in even one single building of the aforementioned size (total floor area of $8,000 \mathrm{~m}^{2}$. Each square-meter of the building interior may consume on average 0.2 to 0.5 robot-hours, depending on a number of variables (the sophistication level of the robotic system, the complexity of the building, the nature of the applications, the adaptability of the materials to robotized work, etc.). Thus, the previously used modelbuilding, with its $8,000 \mathrm{~m}^{2}$ of floor area, may utilize 1,600 to 4,000 robot-hours per year; namely - it can employ at least one "full-time-robot", and perhaps more than one, and/or more than for a single shift per day.

For the multipurpose interior robot, the authors can estimate that its value to the user (see Table 1) will be at the minimum c. $\$ 100,000$, if it will be employed only 1,000 hours per year and save the wages of 1.5 workers, to over $\$ 300,000$ if it will be employed for 1,500 hours per year and save the wages of 3 workers. Both estimates used $\$ 25$ per hour as labor cost. 
For lower labor cost, however, the value of the robot to the user decreases almost proportionally. The purchase price of a commercial robot, like TAMIR, (with tools and peripheral systems) is estimated by the authors within the range of $\$ 100,000-\$ 150,000$. Hence from the user's perspective, it is already economically feasible in countries with high wages, and will gradualy become more-and-more feasible in countries with lower wages, as its efficiency and reliability improve, and its cost - reduced. The multipurpose (versus the singlepurpose) approach has gained strength in recent R\&D efforts by many teams [e.g. $2,3,5,10,12]$.

One must, however, take into account that the efficient employment of an interior finishing robot, with the envisioned economic benefits, requires considerable adaptations of the building design to the constraints of the robotized work. This requires [22], among other measures, due attention to small work spaces, to entries and passages of sufficient width, proper sequencing of the construction works and carefully planned supply of work materials.

\section{5: Assembling-handling robot}

A special case in this respect is the handling assembling robot. Unlike the other robot types - this one does not replace manual labor but actually improves the performance of a conventional mechanized crane by introducing automated control systems, and stabilizing devices [14]. The usual work-cycle of such robot/crane system will consist of picking the load at its origin, moving it to its designated location, discharging it, and - moving back to the same, or to a different origin to pick-up a new load. The first feature assists the robot/crane in bringing the load to its precise location and saves the usual "trial and error" movements of the operator. The other, saves the swinging of the load at the location before its actual deposition as required. Both types of savings are repeated twice for each work cycle - at the origin and the destination.

Each feature - the automated system and the stabilizing device has its own particular cost and its own economic contribution in shortening the robot/crane's work cycle. The cost of each device can be be assessed once its technological nature is determined. The benefit is more difficult to assess. At the minimum - when the continuous work of the robot/crane is not critical to the work progress - the value of the time saved is merely the direct cost of the wages of the operator and of the energy. At the maximum - when the pace of the robot/crane is critical for work progress on site - the savings may amount to the total cost of the sytem - the costs of capital, interest, maintenance, wages of the teams served by the crane etc., as explained before. Based on measurements [13], the total time savings may amount to $30 \%$ of the work cycle, and save the wages of 1-5 workers during its operating time.
The direct value of the automatic feature, according to these estimates, varies between a minimum of $\$ 24,000$ for a non-busy crane with 500 operating hours per year, that saves the wage of a single worker; through medium savings of c. $\$ 128,000$ for a crane that operates 1,000 hours per year, and saves the wages of 2 workers; up to c. $\$ 300,000$ for a busy crane that operates 1,500 hours per year, and saves the wages of 5 workers. In all these cases - 5 transfers per year were assumed. In the two latter - the added indirect (yet quantifyable in money terms) value may become very substantial due to considerable shortening of the total project duration.

\section{4: Intangible benefits of automation}

The analysis in the previous sections focused on the tangible benefits of robot employment - the productivity gains due to replacement of human labor.

Various studies [ e.g.1, 6, 16, 18, 21] reveal that expectations from robot employment - both in manufacturing and in construction - include benefits such as improvement of work environment, faster completion of the task, better quality of product, raising the morale of employees, and elimination of dangerous jobs.

Although these factors cannot be readily measured in economic terms in a similar manner to labor savings, their indirect economic and managerial implications are very important. These implications and their effect on decision-makers in construction have not been included in this study.

\section{5: Summary and conclusions}

The paper presented a simplified, yet complete, model for the micro-economic analysis of robots employment on building sites. Four types of building robots were analyzed with the aid of a simplified model using the available productivity data, which have been published to-date by building robots developers and users. The analysis referred to the cost of robot emplyment versus the economic benefit of the improved productivity in the particular task performed by the robot. The indirect - non-quantifiable benefits were not considered.

The conclusions that could be drawn from the analysis are as follows:

a. The exterior wall finishing robot. It appears that the employment of the painting robot will be economically feasible, provided that it will be employed at least c. $30 \%-50 \%$ of its time $(500-750$ hours per year) on buildings of appropriate size and configuration. The supply of appropriate buildings may pose difficulties unless the robot is employed by a very 
large contractor, or within a very efficient subcontracted exterior finishing service.

b. The horizontal finishing robot. It appears that a robot in this category will be feasible only if it will be employed, continuously (allowing for the transfer down-time), in buildings erected at a very fast pace.

c. The multipurpose interior finishing robot. This robot can be economically feasible if it will be employed about $60 \%-70 \%$ of its time. Its extent of employment is attained more easily than with the other robot types because of its capacity to perform different types of buildong tasks. On the other hand, it requires buildings with carefully adapted design and construction planning, or buildings with exceptionally large floor area on each level.

d. The assembling - handling robot. This type of robots - if they are based on an automated control of existing mechanized equipment - has potentially the highest additional benefit/cost ratio. This is because of the comparatively low investment in the additional feature of automated or semi-automated control, which results, in turn, in considerable productivity savings.

The analysis also revealed that the first three robot types have economic viability only at considerably high wage rates, that prevail in developed countries. They will not be economic at considerably lower wage rates. On the other hand - the automation of existing handling equipment, which is at the heart of the last robot type will be justified at almost any wage rate.

\section{6: References}

1. Arai, K. (1993). "Images of the Future Development of Automated Construction Technology“, Proceedings of the Tenth International Symposium on Automation and Robotics in Construction, Huston, Texas, pp. 371-378.

2. Berlin, R. (1994). "Development of a Multi-Purpose Mobile Robot for Concrete Surface Processing", Proceedings of the 11th International Symposium on Automation and Robotics in Construction, Brighton, UK, pp. 133-140.

3. Bock, T., and Leyh, W. (1995). "The Robotic Building Construction System", Proceedings of the 12th International Symposium on Automation and Robotics in Construction, Warszawa, Poland, pp. 267-280.

4. Dailey, C. M., Traver, A.E., Wesley, G.L., Hass, C.T., and O'Connor J.T. (1993). "Field Testing of Automated Surfase Finishing System for Large Diameter Storage Tanks“, Proceedings of the Tenth International Symposium on Automation and Robotics in Construction, Huston, Texas, pp. 431-438.

5. Drees, G., Laukemper, J., Pritschow, G., and Dalaker, M. (1991). "Limits to Profitability of Automated Masonry", Proceedings of the 8th International Symposium on Automation and Robotics in Construction, Stuttgart, Germany, pp. 833-842.
6. Everett, J.G. (1995). "True Cost of Construction Accidents: Hidden Incentive for Construction Automation", Proceedings of the 12th International Symposium on Automation and Robotics in Construction, Warszawa, Poland, pp. 19-26.

7. Gokyu, T., Takasu, M., and Fukuda, S. (1996). "Development of Wall Painting Robot", Proceedings of the 13th International Symposium on Automation and Robotics in Construction, Tokyo, Japan, pp. 949-956.

8. Kobayashi, M., Soma, M., and Shigihara, T. (1996). "Development and Implementation of Troweling Robot for Concrete Floor Finishing", Proceedings of the 13th International Symposium on Automation and Robotics in Constructio", Tokyo, Japan, pp. 973-980.

9. Miyajima, T., Terauchi, Sh., Arai, K., and Miyamoto, T. (1996). "Development of a Gondola Type External Wall Painting Robot", Proceedings of the 13th International Symposium on Automation and Robotics in Construction, Tokyo, Japan, pp. 957-962.

10. Miyama, A., Sawada, M., and Suzuki, I. (1994). "Development of a Multifunctional Robot for Installation of Building Exterior and Interior Finishing Materials", Proceedings of the 11th International Symposium on Automation and Robotics in Construction, Brighton, UK, pp. 709-716.

11. Neil, C., Salomonsson, G., and Skibniewski, M. (1993). "Robot Implementation Decision in the Australian Construction Industry", Proceedings of the Tenth International Symposium on Automation and Robotics in Construction, Huston, Texas, pp. 133-140.

12. Pritchow, G., Dalacker, M., Kurtz, M., Gaenssle, M., and Haller, J. (1994). “Application Specific Realisation of a Mobile Robot for On-Site Construction“, Proceedings of the 11th International Symposium on Automation and Robotics in Construction, Brighton, UK, pp. 95-102 .

13. Rosenfeld, Y. (1995). “Automation of Existing Cranes: From Concept to Prototype", International Journal of Automation in Construction, 4(2), pp. 125-138.

14. Rosenfeld, Y., and Berkovitz, S. (1989). "Automation of Existing Tower Cranes - Economic and Safety Examination", Proceedings of the 6th International Symposium on Automation and Robotics in Construction, San Francisco, California, pp. 420-426.

15. Rosenfeld, Y., Warszawski, A., and Zajicek, U. (1993). "Full Scale Building with Interior Finishing Robot", International Journal of Automation in Construction, 2(4), pp. 229-240.

16. Shintani, F., and Yamamoto, M. (1993). "The Study on the Development of Building Construction Robots in Japan", Proceedings of the Tenth International Symposium on Automation and Robotics in Construction, Huston, Texas, pp. 379-382.

17. Takeno, M., Matsumura, A., Sakamoto, Sh., Sakai, Y., and Shirato, A. (1989). "Practical Use of Painting Robot for Exterior Walls of High-Rise Buildings“, Proceedings of the 6th International Symposium on Automation and Robotics in Construction, San Francisco, California, pp. 285-292.

18. Tanijiri, H., Ishiguro, B., Arai, T., Yoshitake, R., Kato, M., Morishima, Y., and Takasaki, N. (1996). "Developpment of Automated Weather-Unaffected Building Construction System“, Proceedings of the 13th 
International Symposium on Automation and Robotics in Construction, Tokyo, Japan, pp. 1009-1018.

19. Terauchi, S., Miyajima, T., Miyamoto, T., Arai, K., and Takizawa, S. (1993). "Development of an Exterior Wall Painting Robot Capable of Painting Walls with Indentations and Protrusions", Proceedings of the Tenth International Symposium on Automation and Robotics in Construction, Huston, Texas, pp. 285-292.

20. Tokioka, S., Ishigami, Sh., Sekiguchi, R., Wada, M., Inagaki, H., and Sakai, S. (1989). "Robotized Painting by the Wall Surface-Finisher Robot (FR-1)“, Proceedings of the 6th International Symposium on Automation and Robotics in Construction, San Francisco, California, pp. 523-530.

21. Warszawski, A. (1990). Industrialization and Robotics in Building, Harper and Row, New-York.

22. Warszawski, A., and Navon, R. (1996). "Survey of Building Robots", Proceedings of the 13th International Symposium on Automation and Robotics in Construction, Tokyo, Japan, pp. 205-212.

23. Warszawski, A., and Rosenfeld, Y. (1993). "Feasibility Analysis of Robotized versus Manual Performance of Interior Finishing Tasks", Proceedings of the Tenth International Symposium on Automation and Robotics in Construction, Huston, Texas, pp. 383-390.

24. Warszawski, A., and Rosenfeld, Y. (1994). "Robot for Interior Finishing in Building: Feasibility Analysis", ASCE Journal of Construction Engineering and Management, 120(1), pp. 132-151. 